\title{
Research on University Collaborative Innovation Model Based on the Three Helix Theory
}

\author{
Yu Liu \\ Dept. politics and public administration \\ University of Electronic Science and technology of China \\ Chengdu, China
}

\author{
Junying Huang \\ Dept. politics and public administration \\ University of Electronic Science and technology of China \\ Chengdu, China
}

\begin{abstract}
The report of the 18th National Congress of the Communist Party of China made it clear that it is necessary to implement the national innovation-driven development strategy and attach more importance to cooperation and innovation. The development strategy of collaborative innovation strengthens the close contact and cooperation among universities, enterprises, government and other intermediary organizations. Based on the three helix theory of collaborative innovation theory, this paper interprets the collaborative innovation model of University, points out the function of the collaborative innovation subjects in the three helix theory, and analyzes the three helix collaborative innovation model dominated by the university. It is concluded that the university-leading center, coupled with the enterprise's industrial technology, the Government's policy support, scientific research ability of the research Institute for collaboration, together with the support of external partners to create a new three-helix collaborative innovation model will play an important role in regional synergy innovation.
\end{abstract}

Keywords-Triple helix theory; university collaborative innovation; innovation mode

\section{INTRODUCTION}

With the rapid development of science and technology, the society has stepped into the era of knowledge economy. In the era of knowledge economy, the effective productivity competition of scientific and technological achievements transformation is very fierce, and technological innovation has become the key to the sustainable and healthy development of economy. At the same time, with the complexity of the development of technology and the integration of innovation mode, the traditional industry university research cooperation mode has been unable to meet the needs of the current technological innovation. The report of the 18th National Congress of the Communist Party of China made it clear that it is necessary to implement the national innovation-driven development strategy and attach more importance to cooperation and innovation, which indicates that collaborative innovation has risen to a national strategy.

Colleges and universities, especially research-oriented universities have strong academic advantages, scientific research ability and rich human resources, in the construction of national innovation system, colleges and universities play a very important role as a combination of talents and technology. In April 2011, Comrade Hu Jintao first proposed to actively promote collaborative innovation, encourage universities to carry out deep cooperation with scientific research institutions and enterprises, and implement collaborative innovation Strategy ${ }^{[1]}$. On this basis, in May 2012, the joint Ministry of Education jointly proposed a special national innovation Strategic plan to enhance the innovation ability of colleges and universities, referred to as "2011 plan". In the theory of collaborative innovation, the three-helix theory, as a typical representative, provides a scientific theoretical basis for the collaborative innovation between universities, enterprises and governments. By exploring the role of multiple subjects in the triple helix theory of collaborative innovation, constructing a new collaborative innovation model based on triple helix theory is of great significance to the rapid and healthy development of regional innovation activities.

\section{THEORETICAL BASIS}

\section{A. Collaborative innovation theory}

In the first half of the twentieth century, innovative theory was made by the Austrian economist, Joseph Alois Schumpeter, a Harvard professor, he first proposed "Innovation Theory" in the book "economic development theory". Innovators combine resources in different ways to create new values. This new combination is often "discontinuous", that is to say, the existing organization may bring forth new ideas. However, most of the innovation is generated outside the current organization, innovation refers to the introduction of a new combination of production factors and production conditions into the production system ${ }^{[2]}$.

At present, innovation has become the fundamental driving force for social progress and economic development, and represents the continuous enhancement of human cognition ability and practical ability. With the complexity of innovation activities, the innovation model of a single subject can no longer meet the needs of social science and technology innovation, and the innovation model has evolved from a single subject to a combination of production, study and research. Synergetics has been introduced into the concept of innovation after the German scientist Heerlen Haken formed the concept of synergies. Synergy refers to the interaction between subsystems in a complex large system, Of the separate role, the formation of $1+1>2$ synergistic effect ${ }^{[3]}$. Therefore, the mode of innovation is transited from the traditional mode of cooperation and research to the collaborative and innovative model with the participation of many subjects. Collaborative innovation mode, through the optimization and integration of resources, in enterprises, governments, universities, scientific

Fund Project: 2018 Sichuan Soft Science Research Project (18RKX0191) 
research institutions, financial institutions, science and technology and other scientific and technological innovation related organizations to support the development of common technology and technological innovation activities and behavior $^{\text {[4] }}$.

\section{B. Triple helix theory}

The concept of triple helix was presented in the early 1950s in the field of biology, in which American genetics is used to describe the relationship between genes, organisms and the environment $^{[5]}$. In the mid 90, Professor Roit Redesdorf of the State University of New York, Henry Etzkowitz and professor of science and Technology of Amsterdam, put forward a famous three-helix theory on the basis of three-helix concept, which concludes that government, enterprise and university are the three elements of the innovation system environment within the knowledge economy society. They are connected according to market requirements, forming a three-helix relationship of three kinds of forces, which is called triple helix theory ${ }^{[6]}$. It breaks through the traditional double helix innovation mode that mainly includes universities and enterprises, and creates a triple helix innovation mode in which universities, industries and governments cooperate with each other. These three main subjects are in the process of innovation with the demand of economic development as a link, through the mutual win-win effect, promoted the development of the overall collaborative innovation. Shown in Fig.1:

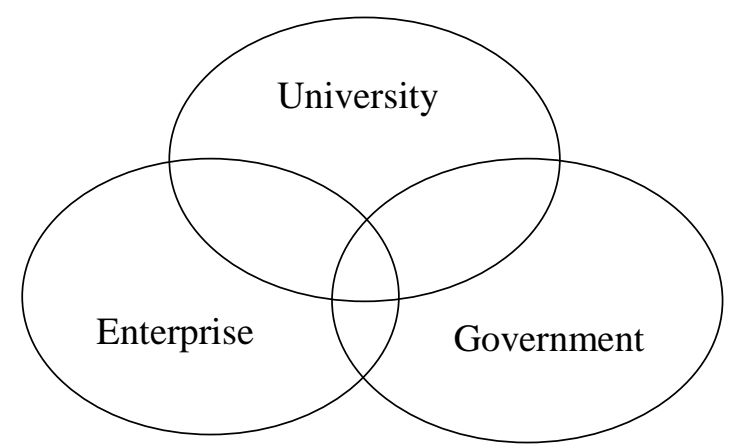

Fig. 1. Triple helix theory model

This theory does not deliberately emphasize who is the main body, but emphasizes the cooperative relationship between the government, industry and university, and emphasizes that the common interests of these groups are to create values for the society in which they are in. Governments, industries and universities can all become leaders, organizers and participants in dynamic systems. Each of these organizations can play a part-time role in other organizations while maintaining its unique function during operation. The three mutually cooperate to achieve the goal of common development.The core of the triple helix theory is that with the advent of a knowledge-based economy, research institutes and universities in the region have become the major intellectual assets and have a higher value. In mature and innovative regions, research institutes and universities have established good interfaces with market economy through research centers, research groups and individuals at the bottom of their organizational structure, and have played a powerful radiation role in technological innovation in the region ${ }^{\text {[7] }}$.

\section{THE MAIN BODY OF COLLABORATIVE INNOVATION BASED ON THE THREE HELIX THEORY}

The innovation subject in the three-helix theory is the behavioral subject in the innovation activity, which has the ability of innovation, and it can make Second innovations according to the change of the innovation system network to adjust its structure and behavior to obtain the corresponding resources. According to the definition of the subject of collaborative Innovation based on the three-helix theory, there are three innovative subjects, including enterprise, university (scientific research institution) and government.

\section{A. Enterprise}

As one of the main bodies of collaborative innovation, enterprises provide more industry support. Enterprises grasp the direction of the development of the market, to marketoriented, comprehensive analysis of market demand, to understand the forefront of the industry dynamics, stimulating targeted technical innovation. For the purpose of making profits, enterprises consider more the principle of maximizing profits. In a certain region, there are usually two kinds of survival modes for enterprises, one is for independent management and the other is for industrial cluster. Independently-run enterprises need to rely on their own independent innovation ability to form a technological advantage and industrial advantages; and cluster-based enterprises can use the mutual cooperation between enterprises for integration and innovation, this collaborative innovation model reduces innovation costs and promote knowledge exchange and creation, to achieve the development of clusterbased enterprises, is conducive to creating an atmosphere of innovation within the region.

\section{B. University (Scientific research institution)}

Universities and other scientific research institutions, with their excellent scientific research ability and rich human resources as an important part of the innovation body, play an important role in the collaborative innovation system. According to their different direction of scientific research universities and other scientific research institutions, bear the different types of advantages of the scientific research functions, including basic research and application-oriented research. Scientific institutions such as universities and colleges provide a high level of talent pool, advanced scientific research facilities and other resources as well as rigorous scientific spirit and complete discipline setting for the collaborative innovation system, which ensure that the main bodies of collaborative innovation are both in terms of hardware and software effective cooperation. In addition, universities, including research-oriented universities and applied universities, are divided into different standards according to their ability to train students. Among them, the research university mainly provides a large number of talents with creativity and scientific research ability, and realizes the creation of scientific research innovation from originality to achievement; compared with the research university, the applied university is based on the cultivation of practical talents with strong learning ability and solid technical ability. To ensure the normal development of scientific research and innovation activities with sufficient manpower support, 
therefore, universities and other scientific research institutions through the provision of a wealth of human resources and scientific research and innovation to cooperate with enterprises achieve the industrialization of scientific research development.

\section{Government}

The government promotes coordinated innovation through the formulation of relevant policies and plays an important role in cooperative innovation activities. On the one hand, the government plays its guiding role by fulfilling its macrocontrol functions and formulating co-innovation policies to guide the coordinated innovation and development in line with the actual conditions in the region to promote regional development. On the other hand, the government uses its economic functions to coordinate the relationships among various subjects in the collaborative innovation system, optimize the channels between various cooperation subjects, and promote effective communication and cooperation among various innovation entities, and eliminate the barriers that lie between enterprises and universities, provide convenient platform guarantee, accelerate the construction of information platform and promote the sustained and healthy development of collaborative innovation activities.

\section{UNIVERSITY-LED COLLABORATIVE INNOVATION MODEL}

University-led collaborative innovation model based on the university as the center of the traditional three helix innovation model. Under the coordination of universities, enterprises, local governments and research institutes, a new cooperative innovation organization -- University Cooperative Innovation Center has been established by signing a cooperation agreement. As shown in Fig.2:

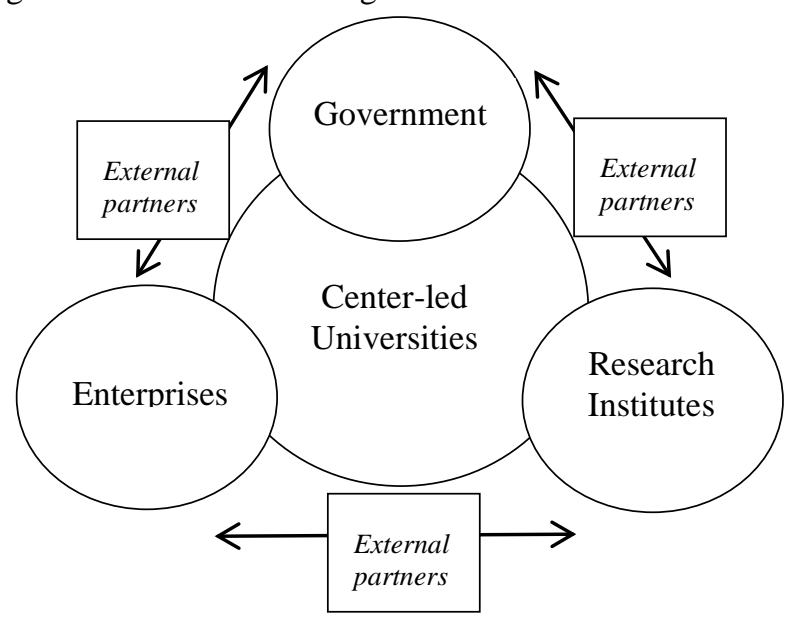

Fig. 2.University-led Collaborative Innovation Model

As can be seen from Fig. 2, with the leading universities as the center factor, the government, enterprises and research institutes respectively establish the corresponding relations with the leading universities. The main body through mutual cooperation forms a set of scientific research institutions, business organizations and local governments, "triple helix" collaborative innovation model. In addition to this, there are many relatively independent and fragmented partners outside the "triple helix" that benefit both from the "triple helix" and from their efficient operation.

\section{A. Center-led universities}

The leading universities are highly prominent in the academic level, scientific research strength and talents in a certain research field. Therefore, they can play the role of the organizer of the cooperative innovation center, combine the resources of different units and disciplines, and form a multidisciplinary resource accumulation advantage, and improve the overall collaborative innovation ability. Attract other participants in collaborative innovation around this advantage to work together and to achieve the rise of the entire collaborative innovation system.

\section{B. Major Collaborators}

The major collaborators mainly include three categories: local government, enterprises and research institutes. Because of the different nature of these collaborators, they have corresponding organizational functions and different motivations for participation. It is because of their different resources and advantages that they can become the leading collaborators in colleges and universities. These major partners are basically excellent in related fields, and interact and integrate under the guidance of leading universities to achieve collaborative innovation.

\section{External partners}

External partners are not only limited to these three organizations, but also may include more diversified partners, such as non-profit organizations. Although these organizations have some disparities in terms of capabilities and benefits compared with universities, enterprises, governments and research institutes, their role can not be ignored. They play an auxiliary role outside the dominant core and the three major partners, providing essential support and assistance for overall co-innovation

Generally speaking, as an extension of the traditional threehelix innovation model, the prominent feature of the three-helix cooperative innovation mode, which is dominated by universities, lies in "one core, three collaborators and many partners". With the university as the leading center factor, coupled with the enterprise's industrial technology, government policy support, scientific research capacity of the institute for collaboration, coupled with external partners for the new threehelix collaborative innovation model will play an important role in regional synergy innovation. Through this collaborative innovation model can promote win-win cooperation,and eventually promoting the continuous development of the entire social innovation system.

\section{CONCLUSION}

The implementation of the "2011 Plan" has led many domestic universities to set up different types of cooperative innovation centers at the national, provincial and municipal levels. This paper interprets the three helix theory in the theory of collaborative innovation, and interprets the new model of collaborative innovation in colleges and universities led by universities. It is concluded that the triple helix theory plays a positive role in promoting the efficiency of regional innovation, 
promoting the cooperation among industry, universities and research institutes and promoting the sustained and rapid economic development in the region. By analyzing the three main bodies of universities, government and enterprises in the collaborative innovation system, this paper proposes that university should be the center of leadership, and the industrial technology of the enterprises, the policy support from the government, the scientific research ability of scientific research institutes should be coordinated and the external cooperation should be combined partnerships for the new triple helix coinnovation model,then this collaborative innovation model will play an important role in regional collaborative innovation.

\section{REFERENCES}

[1] Bu Linhua, An Shi,Fu Qiang. Research on Collaborative Innovation Model Based on Colleges and Universities [J] .Progress of science and technology and Countermeasures2012(11).(In Chinese)
[2] Zhou Qian, Ge Yang. Evolution of science and technology innovation and development of innovative economy $[\mathrm{J}]$. Progress of science and technology and Countermeasures2012(10).(In Chinese)

[3] Yu Zhenting. Research on Evolution Mechanism of Collaborative Innovation System Based on Haken Model - From the Perspective of Triple Helix Theory[D]. Chongqing University 2016.(In Chinese)

[4] Wang Tao, Zhao Chuang, Chen Jing, Li Jizhen. Regional Innovation and Development Model Based on Triple Helix Theory - A Case Study of Tsinghua Yangtze River Delta Research Institute in Zhejiang Province [J]. Innovation and Entrepreneurship Management, 2016(12).(In Chinese)

[5] Zhang Xiuping, Huang Xiaoyin. Triple Helix Theory: An Innovative Paradigm of the Traditional Theory of Industry-University-Research [J] .Journal of Dalian University of Technology (Social Science Edition) 2013 (10).(In Chinese)

[6] Cai Sanfa, Lu Xiaoyan, Chen Long. Influence factors and countermeasures of interaction performance between universities and high-tech zones [J]. Science \& Technology in China Universities, 2017 (7).(In Chinese)

[7] Chen Hongxi,Research on the Cooperation, Mode and Mechanism of Government, Industry, University and Research Based on Triple Helix Theory [J] .Progress in Science and Technology, 2009 (12).(In Chinese) 